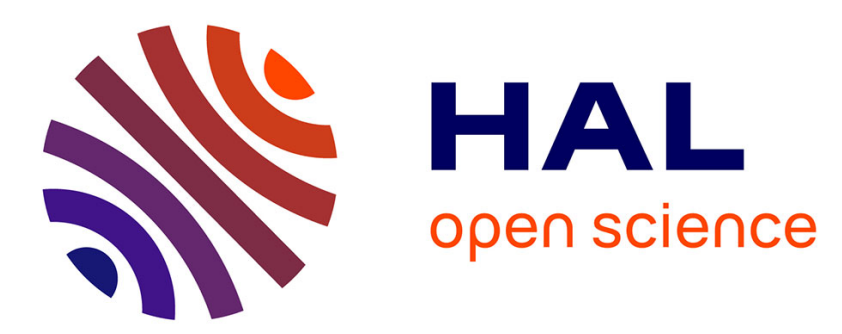

\title{
Photochemical reactivity of phenyl (methyl-tetrazolyl) ketone - hydrogen atom transfer vs. electron transfer
}

Maxime Fréneau, Corentin Lefebvre, Mario Andrés Gómez Fernández, Claire Richard, Norbert Hoffmann

\section{- To cite this version:}

Maxime Fréneau, Corentin Lefebvre, Mario Andrés Gómez Fernández, Claire Richard, Norbert Hoffmann. Photochemical reactivity of phenyl (methyl-tetrazolyl) ketone - hydrogen atom transfer vs. electron transfer. New Journal of Chemistry, 2019, 43 (44), pp.17151-17158. 10.1039/c9nj03061a . hal-02992554

\section{HAL Id: hal-02992554 \\ https://hal.science/hal-02992554}

Submitted on 26 Nov 2020

HAL is a multi-disciplinary open access archive for the deposit and dissemination of scientific research documents, whether they are published or not. The documents may come from teaching and research institutions in France or abroad, or from public or private research centers.
L'archive ouverte pluridisciplinaire HAL, est destinée au dépôt et à la diffusion de documents scientifiques de niveau recherche, publiés ou non, émanant des établissements d'enseignement et de recherche français ou étrangers, des laboratoires publics ou privés. 


\title{
Photochemical reactivity of phenyl (methyl)tetrazolium ketone- Hydrogen atom transfer vs
} electron transfer

\author{
Maxime Fréneau ${ }^{1,2}$, Corentin Lefebvre ${ }^{2}$, Mario Andrés Gomez Fernandez ${ }^{2}$, Claire Richard ${ }^{1 *}$, Norbert \\ Hoffmann ${ }^{2 *}$ \\ ${ }^{1}$ Université Clermont Auvergne, CNRS, SIGMA Clermont, ICCF, F-63000 Clermont-Ferrand, France \\ ${ }^{2}$ CNRS, CNRS, Université de Reims Champagne-Ardenne, ICMR, Equipe de Photochimie, UFR \\ Sciences, B.P. 1039, 51687 Reims, France
}

\section{Abstract:}

Phenyl (methyl)tetrazolium ketone (1) is a synthesis intermediate of tetrazolyloxime fungicides and can be also generated upon their irradiation. Its photolysis is highly solvent dependent which prompted us to investigate more deeply the reaction mechanism. Nanosecond laser flash photolysis of 1 yielded the triplet excited state $\left(\lambda_{\max }=390 / 570 \mathrm{~nm}\right)$ immediately after the pulse. This latter was converted into different secondary species that were identified using their specific reactivity as well as product studies. The ketyl radical $\left(\lambda_{\max }=315 / 475 \mathrm{~nm}\right.$ ) was generated in less than $0.02 \mu \mathrm{s}$ in a good $\mathrm{H}$-donor solvent such as 2-propanol and in around $0.06 \mu \mathrm{s}$ in cyclohexane, a medium $\mathrm{H}$-donor solvent. In 2-propanol, ketyl radicals decayed by a second order reaction to yield pinacol (yield 45\%) while in cyclohexane, they decayed by a second order reaction in the bulk leading to pinacol (yield $21 \%$ ) and by recombination with the cyclohexyl radical in the cage in an apparent first order reaction to generate an adduct (yield $10 \%$ ). In a polar and non $\mathrm{H}$-atom donor solvent as acetonitrile, the zwitterionic diradical $\left(\lambda_{\max }=460 \mathrm{~nm}\right.$ ) was formed in $0.6 \mu$ s with final formation of an atypic dimer. Thus two mechanisms of hydrogen atom transfer are observed. In polar acetonitrile solvent, a twostep-process occurs where the electron is transferred first and the proton follows. In non-polar 2propanol and cyclohexane solvents, a one-step process takes place where the electron and the proton are simultaneously transferred.

Key words: Fungicide, laser flash photolysis, ketyl radical; zwitterionic diradical, hydrogen atom transfer, proton coupled electron transfer.

\section{Introduction}

Plant protection is a key issue in connection with food supply of the mankind. Due to resistance to existing pesticides and environmental requirements and legislation, an increasing number of chemical compounds are synthesized and tested in this regard. Chemical structures of such compounds become more and more complex. Concomitantly with these developments, the weak stability of highly active compounds becomes a decisive problem. In this context, photostability plays a key role. Often, new highly active compounds loss almost completely their activity when exposed to solar light in field. A deep understanding of the mechanisms of corresponding photochemical reactions is necessary for either suppress or at least reduce these processes or to conceive or design photostable molecules and finally diminish the "chemical impact" of plant protection in the environment. 
Recently, we performed a detailed investigation on the photodegradation mechanism of tetrazolyloxime fungicides in order to increase their photostability. ${ }^{1}$ In the course of these investigations, we observed the formation of the aromatic ketone 1 (Scheme 1) among other compounds. Compound $\mathbf{1}$ is also a synthesis intermediate of fungicides such as picarbutrazox (Scheme 1). ${ }^{2}$<smiles>Cn1nnnc1C(=O)c1ccccc1</smiles>

1<smiles>Cn1nnnc1/C(=N\OCc1cccc(NC(=O)OC(C)(C)C)n1)c1ccccc1</smiles>

Picarbutrazox

Scheme 1. Chemical structure of 1 and picarbutrazox

We became interested in the photochemical transformations of ketone 1 because of the possibility of hydrogen atom transfer. In fact in such reactions, hydrogen is often transferred according to two mechanisms: Either the electron and the proton are transferred simultaneously (hydrogen atom transfer, HAT) to the electronically excited reaction partner or the electron is transferred first and the proton follows. ${ }^{3}$ These two elementary steps are part of a larger ensemble of proton coupled electron transfer processes (PCET). ${ }^{4}$,

\section{Experimental}

\section{General information}

Ketone 1 was a gift from Bayer Crop Science. All other reagents were of the highest grade available and used as received. UV-vis spectra were recorded using a Varian Cary 3 spectrophotometer. ${ }^{1} \mathrm{H}$ and ${ }^{13} \mathrm{C}$ NMR spectra were measured in $\mathrm{CDCl}_{3}$ with TMS as an internal standard by using a $600 \mathrm{MHz}\left({ }^{1} \mathrm{H}\right.$ resonance) a Bruker spectrometer. The identification of photoproducts was performed using High resolution mass spectrometry (HRMS) constituted of an Orbitrap Q-Exactive (Thermoscientific) coupled to an ultra-high performance liquid chromatography (UHPLC) instrument Ultimate 3000 RSLC (Thermoscientific). Analyses were carried out in both negative and positive electrospray modes (ESI ${ }^{+}$and $\left.\mathrm{ESI}^{-}\right)$. UHPLC separations were performed using a Phenomenex reversed phase column $\mathrm{C}_{18}$ grafted silica, (100 mm length, $2.1 \mathrm{~mm}$ i.d., $1.7 \mu \mathrm{m}$ particle size). The binary solvent system used was composed of acetonitrile (MeCN) and water acidified with $0.5 \% \mathrm{v} / \mathrm{v}$ formic acid. The gradient program was $5 \%$ ACN for the 7 first min, followed by a linear gradient to $99 \%$ in $7.5 \mathrm{~min}$ and kept constant until $20 \mathrm{~min}$. The flow rate was set at $0.45 \mathrm{~mL} / \mathrm{min}$ and injection volume was $5 \mu \mathrm{L}$. Identification of photoproducts was based on structural elucidation of mass spectra and the use of accurate mass determination obtained with the Orbitrap high resolution. HPLC-UV analyses were performed using a NEXERA XR HPLC-DAD apparatus using the same column and the same HPLC conditions as previously indicated.

\section{Laser flash photolysis}


Transient absorption experiments were carried outon a nano laser flash photolysis spectrometer from Applied Photophysics (LKS.60) using a frequency-quadrupled Nd:YAG laser (Quanta-Ray GCR130-1, pulse duration $9 \mathrm{~ns}$ ). The procedures used for transient absorption spectroscopy measurements have been described previously. ${ }^{10}$ The spectral characteristics of 1 are given in Table $\mathrm{SI}-1$ and Figure SI-1. The maximum of absorption is just below $270 \mathrm{~nm}$ and $\mathbf{1}$ was therefore excited at $266 \mathrm{~nm}$. Peroxodisulfate was used as a chemical actinometer.

\section{Steady state irradiations}

For preparative purpose, irradiations were conducted in a tube placed in a Rayonet $(\lambda=300 \mathrm{~nm})$. For quantum yield measurements, solutions were irradiated in parallel beam using a high pressure mercury lamp equipped with an Oriel monochromator. The photon flux was measured using a radiometer QE65000 from Ocean optics. The percentage of 1 conversion was determined by HPLCUV.

\section{Identification of photoproducts}

Photoproduct 2: Compound 1 (220.5 mg, $1.17 \mathrm{mmol}$ ) was dissolved in $30 \mathrm{~mL}$ of $\mathrm{MeCN}$, poured in quartz tubes and degassed with argon during $10 \mathrm{~min}$. The tubes were then placed in a Rayonet and irradiated at $300 \mathrm{~nm}$ for $40 \mathrm{~min}$. The solvent was evaporated under reduced pressure and the crude was purified by silica column chromatography (petroleum ether/ethyl acetate: $80: 20$ ). Starting material was isolated in $58 \%$ yield $(150 \mathrm{mg}, 0.68 \mathrm{mmol})$ and product 2 was obtained in $26 \%$ yield ( $48.3 \mathrm{mg}, 0.13 \mathrm{mmol})$ as a white solid $\left(R_{f}\right.$ (petroleum ether/ethyl acetate: $\left.70 / 30\right)=0.22$, melting point range : $\left.\left[82.0^{\circ} \mathrm{C}-82.7^{\circ} \mathrm{C}\right]\right) . \mathrm{NMR}^{1} \mathrm{H}\left(600 \mathrm{MHz}, \mathrm{CDCl}_{3}, \mathrm{ppm}\right): \delta=3.74(\mathrm{~s}, 3 \mathrm{H}), 5.50(\mathrm{~s}, 1 \mathrm{H}), 5.52(\mathrm{~d}, \mathrm{~J}=$ $14.82 \mathrm{~Hz}, 1 \mathrm{H}), 5.87(\mathrm{~d}, J=14.82 \mathrm{~Hz}, 1 \mathrm{H}), 7.19(\mathrm{~m}, 3 \mathrm{H}), 7.26(\mathrm{t}, J=6.68 \mathrm{~Hz}, 2 \mathrm{H}), 7.54(\mathrm{t}, J=7.82 \mathrm{~Hz}, 2$ $\mathrm{H}), 7.71(\mathrm{t}, J=7.40 \mathrm{~Hz}, 1 \mathrm{H}), 8.18(\mathrm{~d}, J=7.87 \mathrm{~Hz}, 2 \mathrm{H}) \mathrm{ppm}$. NMR ${ }^{13} \mathrm{C}\left(150 \mathrm{MHz}, \mathrm{CDCl}_{3}, \mathrm{ppm}\right): \delta=$ $35.18,57.12$, 73.44, 125.36, 128.87, 129.27, 129.50, 131.45, 134.39, 135.60, 136.48, 151.17, 155.35, 182.44 ppm (Figure SI-2). UHPLC-HRMS: $\mathrm{m} / \mathrm{z}=377.1463$ in $\mathrm{ES}^{+}$.

Photoproduct 3 in 2-propanol (i-PrOH): Compound 1 (92 mg, $0.49 \mathrm{mmol}$ ) was dissolved in $60 \mathrm{~mL}$ of i$\mathrm{PrOH}$, poured in quartz tubes and degassed with argon during $10 \mathrm{~min}$. The tubes are then placed in a Rayonet and irradiated at $300 \mathrm{~nm}$ for $4 \mathrm{~h}$. The solvent was evaporated under reduced pressure and the crude was purified by silica column chromatography (petroleum ether/ethyl acetate: $95 / 5$ to $50 / 50)$. Product 3 was obtained in $46 \%$ yield $\left(85 \mathrm{mg}, 0.22 \mathrm{mmol}\right.$ ) as a white solid ( $R_{f}$ (petroleum ether/ethyl acetate: $80 / 20)=0.76$, brown stain on TLC with vanillin revelator, melting point range : $\left.\left[189.6^{\circ} \mathrm{C}-190.3^{\circ} \mathrm{C}\right]\right) . \mathrm{NMR}^{1} \mathrm{H}\left(600 \mathrm{MHz}, \mathrm{CDCl}_{3}, \mathrm{ppm}\right): \delta=3.89(\mathrm{~s}, 3 \mathrm{H}), 6.85(\mathrm{~d}, J=7.54 \mathrm{~Hz}, 4 \mathrm{H}), 7.07$ $(\mathrm{s}, 2 \mathrm{H}), 7.13(\mathrm{t}, J=7.78 \mathrm{~Hz}, 4 \mathrm{H}), 7.25(\mathrm{t}, J=7.40 \mathrm{~Hz}, 2 \mathrm{H}) \mathrm{ppm} . \mathrm{NMR}^{13} \mathrm{C}\left(150 \mathrm{MHz}, \mathrm{CDCl}_{3}, \mathrm{ppm}\right): \delta=$ $35.55,79.07,127.12,127.45,128.78,134.29,157.70$ ppm (Figure SI-3). UHPLC-HRMS: $\mathrm{m} / \mathrm{z}=379.1618$ in $\mathrm{ES}^{+}$and 377.1485 in $\mathrm{ES}^{-}$.

Photoproduct 3 in n-heptane: Compound 1 (96 mg, $0.51 \mathrm{mmol}$ ) was dissolved in $110 \mathrm{~mL}$ of nheptane, poured in quartz tubes and degassed with argon during $10 \mathrm{~min}$. The tubes were then placed in a Rayonet and irradiated at $300 \mathrm{~nm}$ for $2 \mathrm{~h} 30$. The solvent was evaporated under reduced pressure and the crude was purified by silica column chromatography (petroleum ether/ethyl acetate: $95 / 5$ to $50 / 50$ ). Product 3 was obtained in $15 \%$ yield $(29 \mathrm{mg}, 0.08 \mathrm{mmol}$ ) as a white solid.

Photoproduct 4: Compound 1 (220.2 mg, $1.17 \mathrm{mmol}$ ) was dissolved in $80 \mathrm{~mL}$ of cyclohexane, poured in quartz tubes and degassed with argon during $10 \mathrm{~min}$. The tubes were then place in a Rayonet and irradiated at $300 \mathrm{~nm}$ for $6 \mathrm{~h}$. The solvent was evaporated under reduced pressure and the crude was purified by silica column chromatography (petroleum ether/ethyl acetate: 90:10). Stains on TLC 
plates were revealed with vanilline. Product 3 was obtained as major product in $21 \%$ yield $(94 \mathrm{mg}$, $0.25 \mathrm{mmol}$ ) as a white solid. Minor product 4 was obtained in $10 \%$ yield ( $31 \mathrm{mg}, 0.11 \mathrm{mmol}$ ) as a clear liquid $\left(R_{f}\right.$ (petroleum ether/ethyl acetate : 80/20) $=0.30$, blue stain on TLC with vanillin revelator). $\mathrm{NMR}^{1} \mathrm{H}\left(600 \mathrm{MHz}, \mathrm{CDCl}_{3}, \mathrm{ppm}\right): \delta=0.99$ (qd, $\left.J=3.48,12.42 \mathrm{~Hz}, 1 \mathrm{H}\right), 1.13(\mathrm{~m}, 2 \mathrm{H}), 1.24$ $(\mathrm{m}, 2 \mathrm{H}), 1.47(\mathrm{qt}, J=3.48,13.02 \mathrm{~Hz}, 1 \mathrm{H}), 1.70(\mathrm{~m}, 2 \mathrm{H}), 1.82(\mathrm{~m}, 1 \mathrm{H}), 2.05(\mathrm{~d}, J=12.18 \mathrm{~Hz}, 1 \mathrm{H}), 2.7$ $(\mathrm{tt}, J=2.82,12.12 \mathrm{~Hz}, 1 \mathrm{H}), 2.85(\mathrm{~s}, 1 \mathrm{H}), 3.83(\mathrm{~s}, 3 \mathrm{H}), 7.30(\mathrm{~m}, 5 \mathrm{H}) \mathrm{ppm} . \mathrm{NMR}^{13} \mathrm{C}\left(150 \mathrm{MHz}, \mathrm{CDCl}_{3}\right.$, ppm) : $\delta=26.24,26.29,26.36,27.73,35.72,46.82,77.53,125.43,127.90,128.58,140.32,157.57$ ppm (Figure SI-4). UHPLC-HRMS: $\mathrm{m} / \mathrm{z}=273.1703$ in $\mathrm{ES}^{+}$.

\section{Results}

\section{Product studies}

When compound 1 was irradiated in acetonitrile at $\lambda=300 \mathrm{~nm}$, we observed the formation of compound 2. The reaction was stopped at a conversion of $42 \%$ (Scheme 2). Further irradiation led to a very unselective transformation and the complex product mixture could not be characterized. Irradiation of compound $\mathbf{1}$ in $\mathrm{i}-\mathrm{PrOH}$, cyclohexane or $\mathrm{n}$-heptane yielded compound $\mathbf{3}$. In cyclohexane, compound $\mathbf{4}$ was also obtained in small amounts. Formation of compound $\mathbf{3}$ resembles the wellknown photo-pinacolization ${ }^{6}$ while the formation of compound $\mathbf{2}$ is unusual.

Compound 3 results from a reaction in which hydrogen atom transfer plays a central role. In such processes stable ketyl radicals are formed and dimerization leads to pinacol products such as $\mathbf{3}$. It must be noted that the best yield of this product is observed when i-PrOH was used as an efficient $\mathrm{H}$ atom donor and as a solvent. In the case of the poor hydrogen atom donor $n$-heptane, the formation of $\mathbf{3}$ is much less efficient. In cyclohexane that is a medium hydrogen atom donor, the yield is intermediate. Interestingly, the cyclohexyl radicals resulting from the oxidation of the solvent are able to combine with the ketyl radicals generated from ketone 1 to form compound $\mathbf{4}$. The behavior of $\mathbf{1}$ in $\mathrm{MeCN}$ used as a polar solvent with poor hydrogen atom donation properties looks very atypic. The detection of $\mathbf{2}$ suggests the intermediary formation of a methyl radical and a ketyl radical localized on two different starting molecules. We hypothesized that photochemical electron transfer is involved in the formation of these radicals and of compound $\mathbf{2}$.

In order to get a deeper insight into the reaction mechanism, a detailed physico-chemical investigation was performed. 

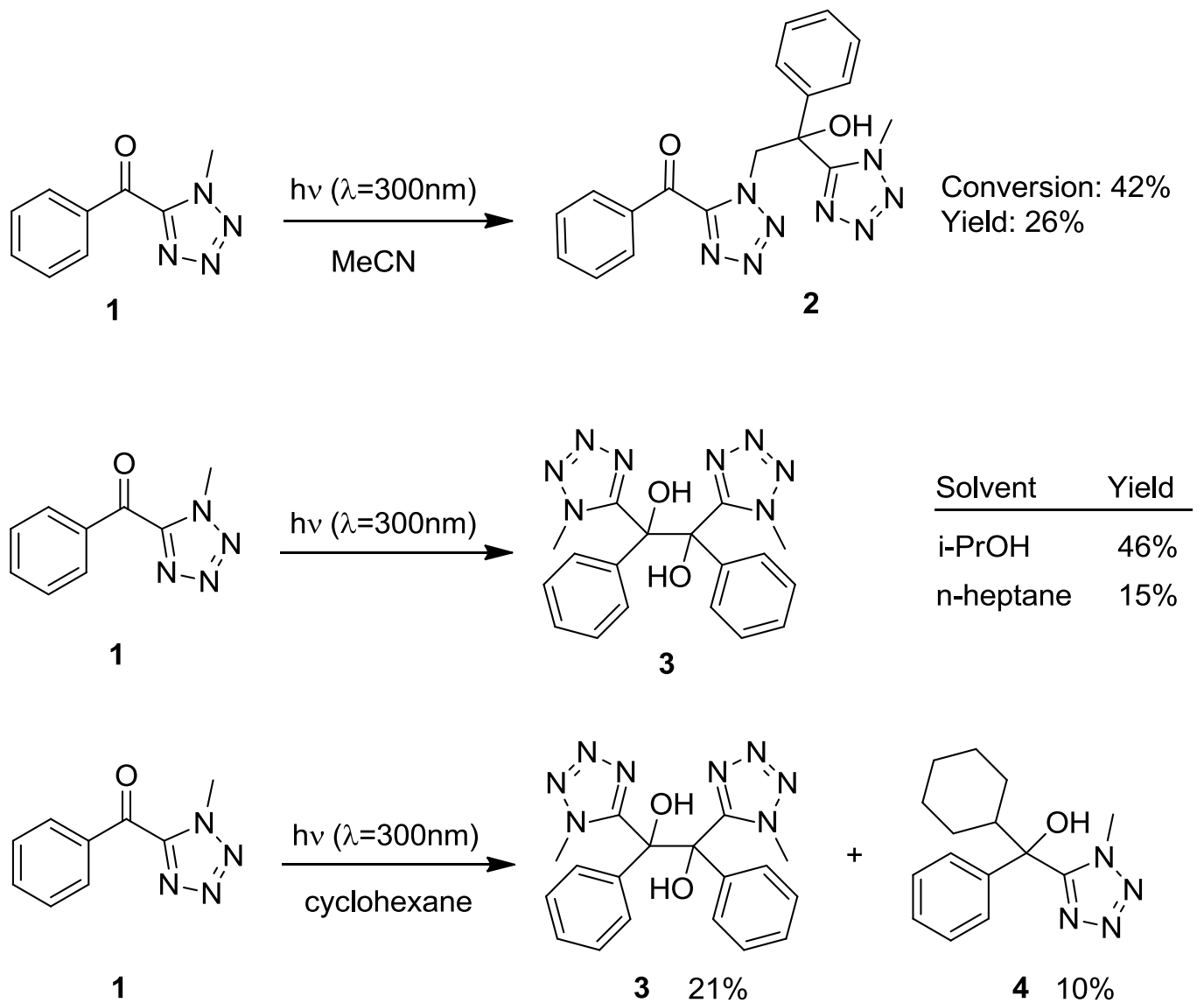

Scheme 2. Photochemical transformations of the aromatic ketone 1.

\section{Formation of the triplet excited state.}

The laser flash photolysis of $\mathbf{1}$ at $266 \mathrm{~nm}$ yielded the same transient species in $\mathrm{MeCN}$, i-PrOH, cyclohexane and $\mathrm{n}$-heptane. It was observed immediately following the laser pulse and showed two maxima at 390 and $570 \mathrm{~nm}$ (Figure 1). By plotting the absorbance measured at $380 \mathrm{~nm}$ at the end of the pulse against the pulse energy, one got an $\varepsilon \times \Phi$ product of $3300 \pm 500 \mathrm{M}^{-1} \mathrm{~cm}^{-1}$ in cyclohexane and $\mathrm{n}$-heptane, where $\varepsilon$ is the molar absorption coefficient of the species at $380 \mathrm{~nm}$ and $\Phi$, the quantum yield of the transient formation. The assignment of this transient to the triplet excited state, ${ }^{3} \mathbf{1}^{*}$, was made possible by studying its reactivity with oxygen and anthracene. In MeCN, the lifetime of the transient was reduced by a half upon deoxygenation of the solution $(0.34 \mu \mathrm{s}$ in air-saturated solution against $0.6 \mu$ s in argon-saturated solution) demonstrating the scavenging effect of oxygen (Figure 2). Moreover, the irradiation of $\mathbf{1}$ in the presence of anthracene led to an accelerated decay of the transient at $380 \mathrm{~nm}$ and to the formation of the triplet excited state of anthracene well visible at 420 $\mathrm{nm}$ (Figure SI-5). This result brings evidence that an energy transfer took place between the transient and ground state anthracene and confirms that the transient was ${ }^{3} 1^{*}$. The quantum yield of ${ }^{3} 1^{*}$ formation was estimated to be equal to $0.26 \pm 0.05$. 


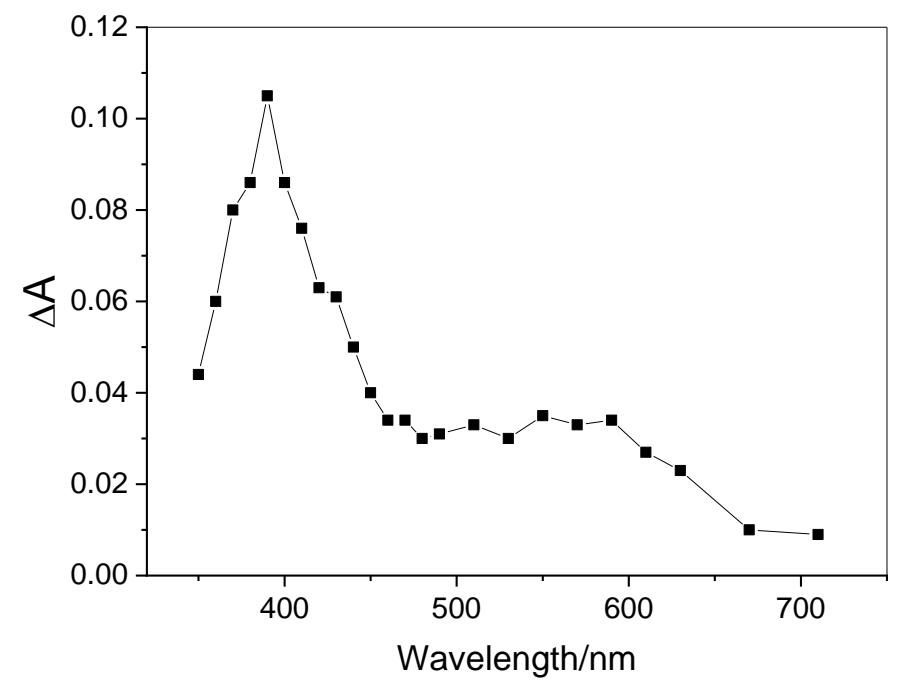

Figure 1 : Transient absorption spectrum measured immediately after the pulse by excitation of 1 at $266 \mathrm{~nm}$ in aerated MeCN. (1) $=6 \times 10^{-5} \mathrm{M}, \mathrm{A}_{266}=0.77$

\section{Reactivity of the triplet.}

The decay of ${ }^{3} 1^{*}$ in deoxygenated medium obeyed an apparent first order kinetics, but was solventdependent. As shown in Table 1, the apparent first-order decay rate constant varied in the order $\mathrm{MeCN} \sim \mathrm{n}$-heptane < cyclohexane < i-PrOH, i.e. increased with the H-donor capacity of the solvent. In pure i-PrOH, the decay of ${ }^{3} 1^{*}$ was too fast to be accurately measured. The rate constant of reaction of ${ }^{3} 1^{*}$ with $\mathrm{i}-\mathrm{PrOH}$ was therefore measured in $\mathrm{MeCN} / \mathrm{i}-\mathrm{PrOH}$ mixtures. From the linear dependence of the apparent first-order decay rate constant on i-PrOH concentration, a value of $(4.3 \pm 0.4) \times 10^{6} \mathrm{M}^{-1} \mathrm{~s}^{-1}$ was obtained (Figure SI-6).

\begin{tabular}{|l|c|c|l|l|}
\hline Transient & $\mathrm{MeCN}$ & $\mathrm{n}$-heptane & cyclohexane & i-PrOH \\
\hline $\begin{array}{l}\text { Decay rate } \\
\text { constant of }{ }^{3} \mathbf{1}^{*}\end{array}$ & $(1.8 \pm 0.2) \times 10^{6} \mathrm{~s}^{-1}$ & $(2.0 \pm 0.3) \times 10^{6} \mathrm{~s}^{-1}$ & $\left(1.7 \times 10^{7}\right) \pm 0.3 \mathrm{~s}^{-1}$ & $>5 \times 10^{7} \mathrm{~s}^{-1}$ \\
\hline $\begin{array}{l}\text { Decay rate } \\
\text { constant of } \\
\text { secondary species }\end{array}$ & $\begin{array}{l}1.7 \times 10^{5} \mathrm{~s}^{-1} \\
\mathrm{t}_{1 / 2}=4.1 \mu \mathrm{s}\end{array}$ & - & $\begin{array}{l}2.5 \times 10^{5} \mathrm{~s}^{-1}(\text { main } \\
\text { process } \sim 80 \%) \\
2 \mathrm{k} / \varepsilon_{330}=6.5 \times 10^{5} \\
\mathrm{~cm}^{-1} \mathrm{~s}^{-1}(\text { minor } \\
\text { process } \sim 20 \%) \\
\mathrm{t}_{1 / 2} \sim 3.5 \mu \mathrm{s}\end{array}$ & $\begin{array}{l}2 \mathrm{k} / \varepsilon_{330}=2.7 \times 10^{5} \\
\mathrm{~cm}^{-1} \mathrm{~s}^{-1} \\
\mathrm{t}_{1 / 2} \sim 40 \mu \mathrm{s}\end{array}$ \\
\hline $\begin{array}{l}\text { Quantum yield of 1 } \\
\text { photolysis }\end{array}$ & $0.17 \pm 0.03$ & & $0.064 \pm 0.02$ & 0 \\
\hline
\end{tabular}

Table 1 : Decay rate constants of the transients in deoxygenated solvents and quantum yields of 1 photolysis air air-saturated medium. $(\mathbf{1})=6 \times 10^{-5} \mathrm{M}$

The reactivity of ${ }^{3} 1^{*}$ with 1 was also investigated using concentrations of 1 up to $10^{-2} \mathrm{M}$. In this set of experiments, the solutions were excited at $355 \mathrm{~nm}$ to reduce the absorption of solutions. The decay 
rate constant of ${ }^{3} 1^{*}$ increased linearly with 1 concentration. A bimolecular reaction rate constant of $(9.2 \pm 0.9) \times 10^{7} \mathrm{M}^{-1} \mathrm{~s}^{-1}$ was deduced from the linear plot.

194

\section{Characterization of the secondary transients.}

196

197

Secondary species were detected after the decay of ${ }^{3} \mathbf{1}^{*}$ in i-PrOH, cyclohexane and MeCN. In MeCN, the growth of the secondary species was slow and kinetically correlated with the decay of ${ }^{3} 1^{*}$ (Figure 2). Moreover, the addition of oxygen accelerated the secondary transient formation while reducing the intensity of the signal in accordance with a partial scavenging of ${ }^{3} \mathbf{1}^{*}$ by oxygen (Figure 2 ). This fully confirmed the mother-daughter relationship between the two species. In i-PrOH and cyclohexane, the formation of the secondary transient and the ${ }^{3} 1^{*}$ decay were both very fast in agreement with a relationship between the two species (Figure SI-7).

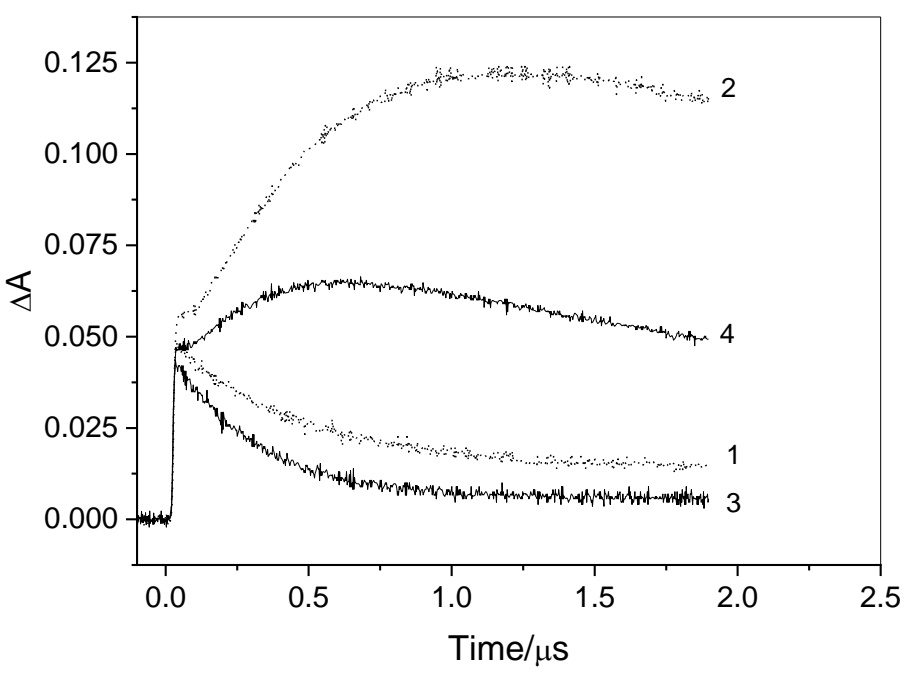

Figure 2: Decay of ${ }^{3} 1^{*}$ at $550 \mathrm{~nm}$ and growth of the secondary transient at $460 \mathrm{~nm}$. Curves 1 and 2 in deoxygenated $\mathrm{MeCN}$ and curves 3 and 4 in air-saturated $\mathrm{MeCN}$. (1) $=6 \times 10^{-5} \mathrm{M}, \mathrm{A}_{266}=0.77$

In i-PrOH and cyclohexane, the secondary species absorption spectra were very similar. They presented two absorption bands with maxima located at 310-320 nm and 470-480 nm. For these two maxima, the intensity of the absorption is twice higher in $\mathrm{i}-\mathrm{PrOH}$ than in cyclohexane reflecting a more efficient formation in the former solvent. The secondary transient formed in MeCN was different as it showed an absorption band with maximum at $460 \mathrm{~nm}$ and no visible other band within the wavelength range $310-350 \mathrm{~nm}$ (Figure 3). 


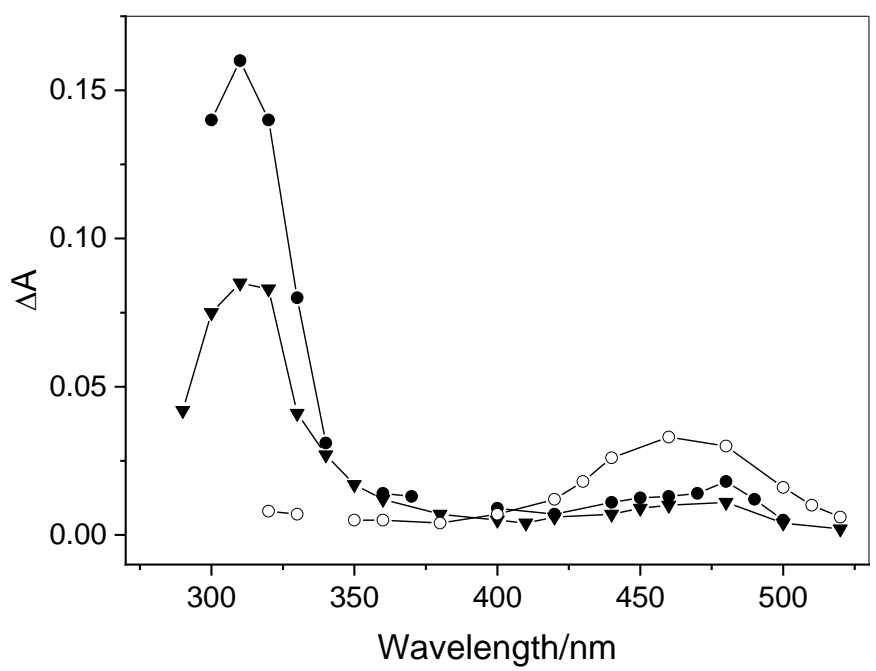

Figure 3: Transient absorption spectra measured by excitation of 1 at $266 \mathrm{~nm}$ in argon-saturated i$\operatorname{PrOH}(\nabla)$, cyclohexane $(\mathbf{O})$, and acetonitrile $(\bigcirc)$ after the disappearance of ${ }^{3} 1^{*}: 100$ ns following the pulse in $\mathrm{i}-\mathrm{PrOH}, 350 \mathrm{~ns}$ in cyclohexane, and $2 \mu \mathrm{s}$ in $\mathrm{MeCN}$. The other experimental conditions are the same as those in Figure 1.

The lifetimes and reactivities of the secondary species are presented in Table 1 . The secondary species formed in i-PrOH and cyclohexane were not detected in air-saturated medium, probably due to a fast quenching by oxygen. In deoxygenated i-PrOH, the secondary species decayed by a second order kinetics with a rate constant equal to $2 \mathrm{k} / \varepsilon=2.7 \times 10^{5} \mathrm{~cm}^{-1} \mathrm{~s}^{-1}$ at $330 \mathrm{~nm}$ (Figure SI-8). Based on these kinetic data, on the formation of pinacol 2 and on the known photoreactivity of benzophenones in i-PrOH, the secondary transient can be assigned to the ketyl radical $\mathbf{A}$ (Scheme 3). ${ }^{7}$

In deoxygenated cyclohexane, the decay of the ketyl radical was about 10 -fold faster than in i-PrOH (Table 1, Figure SI-9). The lower viscosity of cyclohexane compared to i-PrOH $\left(0.98 \times 10^{-3} \mathrm{~Pa}\right.$.s against $2.37 \times 10^{-3} \mathrm{~Pa}$.s at $20^{\circ} \mathrm{C}$ ) can only explain a part of this difference. Indeed, $2 \mathrm{k} / \varepsilon$ in cyclohexane at 330 $\mathrm{nm}$ is expected to be equal to $6.5 \times 10^{5} \mathrm{~cm}^{-1} \mathrm{~s}^{-1}$, i.e. 2.4 -fold bigger than in i-PrOH. The fast decay of the ketyl radical in cyclohexane could also be due to a mixture of pseudo-first order and second order kinetics. This is possible if we make the hypothesis that a part of the ketyl radicals $\mathbf{A}$ react with the cyclohexyl radicals $\mathbf{B}$, formed after the $\mathrm{H}$ atom abstraction, before escaping the cage. This recombination would be the first order contribution of the decay. It is fully in agreement with the detection of 4 . Once in the bulk, the ketyl radical would decay by a second order kinetics. Such a dual kinetics was nicely described in the photolysis of benzophenone dissolved in soft rubber poly(ethylene-co-butylene) films. ${ }^{8}$ By fitting the ketyl radical decay taking $2 \mathrm{k} / \varepsilon_{330}=6.5 \times 10^{5} \mathrm{~cm}^{-1} \mathrm{~s}^{-1}$, we obtained that about $80 \%$ of the reaction corresponds to the first order geminate recombination in the cage and $20 \%$ to the bimolecular recombination in the bulk. When 1 was irradiated in i-PrOH, no geminate recombination was observed. This is in accordance with the literature data that reports the exclusive pinacols formation for benzophenones irradiated in i- $\mathrm{PrOH}^{9}{ }^{9}$ 
The formation of $\mathbf{3}$ in $\mathbf{n}$-heptane suggests that the ketyl radical $\mathbf{A}$ is also formed in this solvent. However, we could not observe it at $480 \mathrm{~nm}$. It is probably formed in too small amounts to be detected.

The secondary species formed in $\mathrm{MeCN}$ is not the ketyl radical A for several reasons. First, its transient absorption spectrum was different from that of the ketyl radical. Moreover, it reacted with oxygen but with a moderate rate constant $\left(2.9 \times 10^{7} \mathrm{M}^{-1} \mathrm{~s}^{-1}\right)$ (Figure SI-10). In deoxygenated medium, it decayed by a clean pseudo-first order kinetics with a rate constant of $1.7 \times 10^{5} \mathrm{~s}^{-1}$. The last peculiarity of the secondary transient formed in $\mathrm{MeCN}$ is its reactivity with water. A significant enhancement on its decay was measured upon the addition of water ( 4 and $30 \%, v / v$ ) (Figure 4 ) while the ketyl radical was not affected by water in i-PrOH. This result suggests an ionic character for the species and we concluded that it is the zwitterionic diradical.

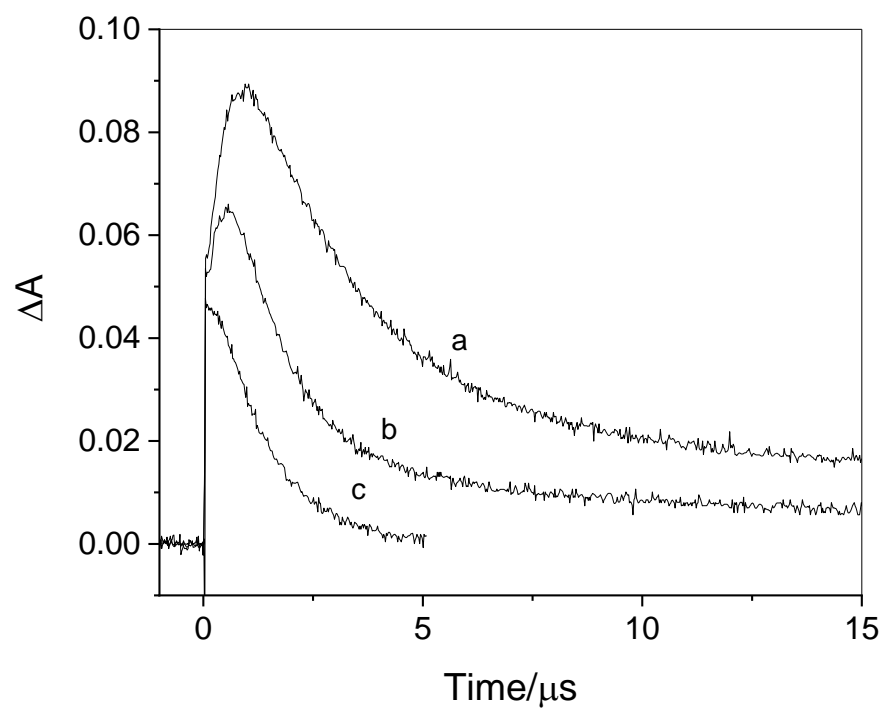

Figure 4 : Decay at $460 \mathrm{~nm}$ of the secondary species formed in MeCN in the absence of water (a), in the presence of $4 \%$ of water (b), in the presence of $30 \%$ of water (c). The other experimental conditions are the same as those in Figure 1.

\section{Mechanisms.}

In $\mathrm{i}-\mathrm{PrOH}$, the formation of a ketyl radical by $\mathrm{H}$-atom abstraction from $\mathrm{i}$-PrOH is very usual (scheme 3). This is consistent with the known photoreactivity of aromatic carbonyls in H-donor solvents. ${ }^{10}$ In the presence of oxygen, the ketyl radical would give the $\mathrm{H}$ atom to oxygen ${ }^{11}$ and regenerate 1 . This explains the absence of phototransformation of $\mathbf{1}$ in air-saturated medium (Table 1 ). In the absence of oxygen, the recombination of two ketyl radicals $\mathbf{A}$ would lead to pinacol $\mathbf{3}$. This pinacolisation is fully in line with the observed second order decay kinetics observed by laser flash photolysis. 
<smiles>[CH][CoH]</smiles>

Scheme 3: Formation of pinacol $\mathbf{3}$ via the ketyl radical $\mathbf{A}$

In cyclohexane, the formation of the ketyl radical $\mathbf{A}$ also takes place as indicated by the formation of pinacol 3 (Scheme 4). The yield is however lower than in i-PrOH, $21 \%$ against $46 \%$, in accordance with the existence of competitive reactions, in particular the geminate recombination in the cage of solvent. In such a reaction also compound $\mathbf{4}$ is formed by combination of a ketyl radical $\mathbf{A}$ with a cyclohexyl radical $\mathbf{B}$.

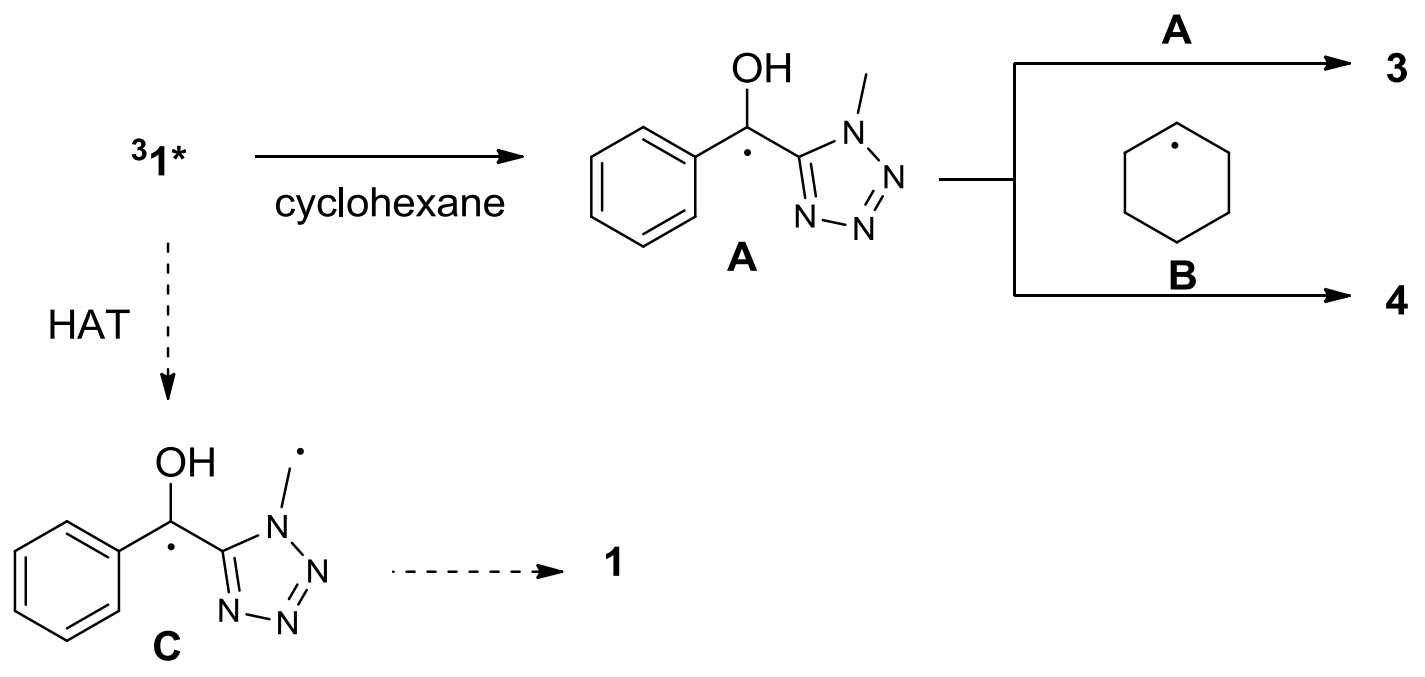

Scheme 4: Formation of pinacol $\mathbf{3}$ and of the adduct $\mathbf{4}$ via the ketyl radical $\mathbf{A}$

In $\mathrm{n}$-heptane, that is a poor $\mathrm{H}$-atom donor solvent, the ketyl radical $\mathbf{A}$ could not be detected in the laser flash photolysis experiments. Yet, photoproduct $\mathbf{3}$ was formed in the preparative product studies. These experiments being conducted at a very high $\mathbf{1}$ concentration, $\mathbf{1}$ might have been the $\mathrm{H}$ donor, since we demonstrated that a non-negligible reaction between ${ }^{3} \mathbf{1}^{*}$ and $\mathbf{1}$ can take place. The high 1 concentration used in preparative reactions has probably affected the photoproducts yields. In particular in cyclohexane where the ketyl radical $\mathbf{A}$ decays by a mixed first order and second order kinetics, increasing 1 concentration is expected to increase the ketyl radical $\mathbf{A}$ concentration and to favor pinacolisation. Due to the poor $\mathrm{H}$-donor capacity of $\mathrm{n}$-heptane, we initially considered as possible to detect in this solvent the neutral diradical $\mathbf{C}$ formed through intramolecular $\mathrm{H}$ atom transfer. ${ }^{12}$ This hypothesis was not confirmed experimentally. Either the reaction does not take place, or this species is too short lived to be detected as shown for other benzophenone derivatives. ${ }^{11}$ 
In $\mathrm{MeCN}$ that is more polar than the other solvents together with a poor $\mathrm{H}$-donor molecule, a very different situation seems to take place. The experimental data are in line with the formation of an ionic intermediary structure that is likely the zwitterionic radical $\mathbf{D}$ formed by an intramolecular electron transfer (Scheme 5). This assignment is confirmed by the specific reactivity of the secondary species formed in MeCN compared that of ketyl radical $\mathbf{A}$.

Under these conditions, we didn't detect a ketyl radical intermediate. As a consequence, we exclude an intermolecular hydrogen transfer from the solvent and suggest an intermolecular hydrogen transfer between the zwitterionic intermediate $\mathbf{D}$ and $\mathbf{1}$ at its ground state (Scheme 5 ). The zwitterionic intermediate $\mathbf{D}$ can be deprotonated leading to a diradical anion $\mathbf{E}$ and the protonated ketone $[\mathbf{H}-\mathbf{1}]^{+}$. An electron is then transferred and the neutral radicals $\mathbf{H}$ and $\mathbf{I}$ are formed. Radical combination leads to the unusual regioisomer of the coupling product $\mathbf{2}$. Alternatively, an electron is transferred first leading to the intermediates $\mathbf{F}$ and $\mathbf{G}$. Proton transfer leads again to the neutral intermediates $\mathbf{H}$ and $\mathbf{I}$. Most probably, the transfer of both particles of the hydrogen atom is coupled (proton coupled electron transfer, PCET). As the intermolecular hydrogen transfer is favored in a polar solvent an increase of the polarity in the transition state of the PCET step is possible. In a corresponding intermolecular step (HAT), the neutral diradical intermediate $\mathbf{C}$ would be formed as depicted in Scheme 4, this is not the case. Furthermore, it must be pointed out that the one step hydrogen transfer needs a highly structured transition state with highly negative $\Delta \mathrm{S}^{\neq}$values while for the electron transfer in a two-step hydrogen transfer this value is close to zero. ${ }^{13}$ The herein described reaction compound $\mathbf{1}$ leading to the unusual coupling product $\mathbf{2}$ is therefore directly linked to the formation of the zwitterionic diradical $\mathbf{D}$. 


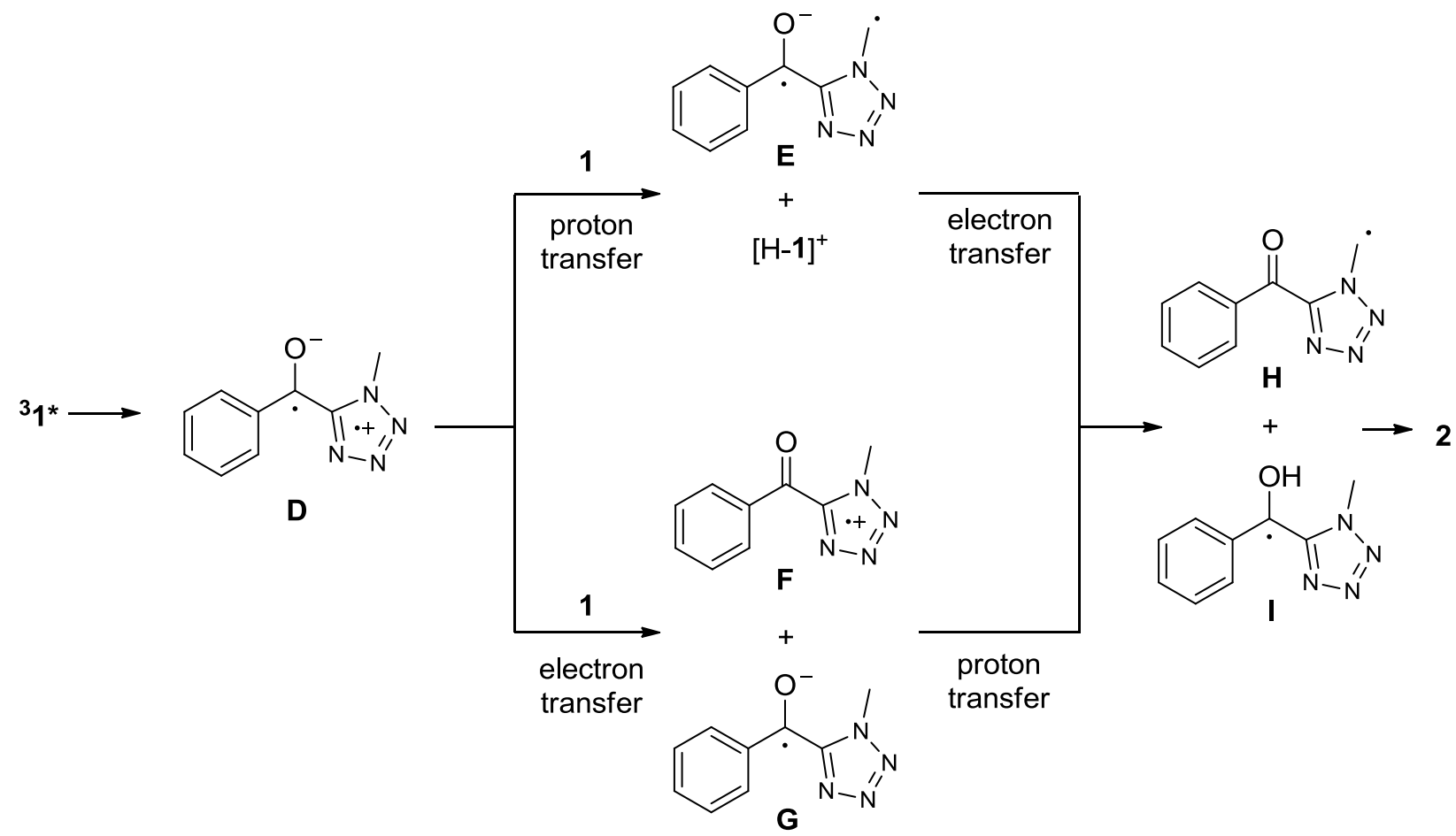

Proton Coupled Electron Transfer

Scheme 5: Formation of dimer $\mathbf{2}$ via the zwitterionic diradical D involving proton coupled electron transfer.

\section{Conclusion}

The photochemical reactivity of phenyl (methyl)tetrazolium ketone 1 has been studied in detail by means of preparative product studies and laser flash photolysis. When efficient hydrogen atom donor compounds such as isopropanol are used as solvents, ketyl radicals are formed which dimerize leading to photopinacol analogue products as it has previously been reported for aromatic ketones such as benzophenone. A completely different intermediate is formed when ketone $\mathbf{1}$ is irradiated in acetonitrile. This intermediate possesses a zwitterionic character. A proton coupled electron transfer from this intermediate to $\mathbf{1}$ at its ground state is suggested to explain the formation of the unusual final product 2 .

\section{Acknowledgments}

We would like to thank Jye-Shane Yang (National Taiwan University, Taipei) for helpful discussions. We are grateful for financial support from the University of Reims, the French Ministry of Higher Education, Research and Innovation and to Bayer SA (Lyon) for financial support. 
${ }^{1}$ M. Fréneau, P. de Sainte Claire, N. Hoffmann, J.-P. Vors, J. Geist, M. Euvrard, C. Richard, Phototransformation of Tetrazoline oxime ethers: Photoisomerization vs photodegradation, RSC Adv. 2016, 6, 5512-5522. M. Fréneau, N. Hoffmann, J.-P. Vors, P. Genix, C. Richard, P. de Sainte Claire, Phototransformation of Tetrazoline Oxime Ethers - Part2: Theoretical Investigation, RSC Adv. 2016, 6, 63965-63972.

${ }^{2}$ D. Ichinari, A. Nagaki, J. Yoshida, Generation of hazardous methyl azide and its application to the synthesis of key-intermediates of picarbutarox, Bioorg. Med. Chem. 2017, 25, 6224-6228. T. Kobori, H. Kondo, H. Tsuboi, K. Akiba, A. Koiso, T. Otaguro, H. Nakayama, H. Hamano, A. Ono, T. Asada, Tetrazoyl oxime derivative and agricultural chemical containing the same as active ingredient, EP $1426371 \mathrm{A1}, 2002$

${ }^{3}$ N. Hoffmann, Electron and hydrogen transfer in organic photochemcial reactions, J. Phys. Org. Chem. 2015, 28, 121-136. N. Hoffmann, Photochemical Electron and Hydrogen Transfer in Organic Synthesis: The control of Selectivity, Synthesis 2016, 48, 1782-1802.

${ }^{4}$ S. Y. Reece, J. M. Hodgkiss, JA. Stubbe, D. G. Nocera, Photon-coupled electron transfer: the mechanistic underpinning for radical transport and catalysis in biology, Phil. Trans. R. Soc. B, 2006, 361, 1351-1364. S. Hammes-Schiffer, A. A. Stuchebrukhov, Theory of Coupled Electron and Proton Transfer Reactions, Chem. Rev. 2010, 110, 6939-6960. D. R. Weinberg, C. J. Galiardi, J. F. Hull, C. F. Murthy, C. A. Kent, B. C. Westlake, A. Paul, D. H. Ess, D. G. McCafferty, T. J. Meyer, Proton-Coupled Electron Transfer, Chem. Rev. 2012, 112, 4016-4093. A. Migliore, N. F. Polizzi, M. J. Therien, D. N. Beratan, Biochemistry and Theory on Proton-Coupled Electron Transfer, Chem. Rev. 2014, 114, 3381-3465.

${ }^{5}$ D. C. Miller, K. T. Tarantino, R. R. Knowles, Proton-Coupled Electron Transfer in Organic Synthesis:

Fundamentals, Applications, and Opportunities, Top. Curr. Chem. (Z) 2016, 374, 30, (1-59). N. Hoffmann, Proton-Coupled Electron Transfer in Photoredox Catalytic Reactions, 2017, 2017, 1982-1992. J. Ma, X. Zhang, D. L. Phillips, Time-Resolved Spectroscopic Observation and Characterization of Water-Assisted Photoredox Reactions of Selected Aromatic Carbonyl Compounds, Acc. Chem. Res. 2019, 52, 726-737. E. Fava, M. Nakajima, A. L. P. Nguyen, M. Rueping, Photoredox-Catalyzed Ketyl-Olefin Coupling for the Synthesis of Substituted Chromanols, J. Org. Chem. 2016, 81, 6959-6964.

${ }^{6}$ M. B. Rubin, Photoinduced Intermolecular Hydrogen Abstraction Reactions of Ketones, In CRC Handbook of Organic Photochemistry and Photobiology (W. M. Horspool, P. S. Song, Eds.), CRC Press, Boca Raton, 1995, P. 430.

${ }^{7}$ N. J. Turro, V. Ramamurthy, J. C. Scaiano, Modern Molecular Photochemistry of Organic Molecules, University Science Books, Sausalito, 2010, p. 640

${ }^{8}$ P. P. Levin, A. F. Efremkin, I. V. Khudyakov, Kinetics of benzophenone ketyl free radicals recombination in a polymer: reactivity in the polymer cage vs. reactivity in the polymer bulk, Photochem. Photobiol. Sci. 2015, 14, 891-896.

${ }^{9}$ W. M. Moore, G. S. Hammond, R. P. Foss, Mechnisms of Photoreactions in Solutions. I. Reduction of Benzophenone by Benzhydrol, J. Am. Chem. Soc. 1961, 83, 2789-2794. J. N. Pitts, R. L. Letsinger, R. P. Taylor, J. M. Patterson, G. Recktenwald, R. B. Martin, Photochemical Reactions of Benzophenone in Alcohols J. Am. Chem. Soc. 1959, 81, 1068-1077.

${ }^{10}$ F. Bonnichon, C. Richard, Phototransformation of 3-hydroxybenzonitrile in water, J. Photochem. Photobiol. A 1998, 119, 25-32.

11 J. C. Scaiano, Laser Flash Photolysis Studies of the Reactions of Some 1,4-Biradicals, Acc. Chem. Res. 1982, 15, 252-258.

${ }^{12}$ This reaction step would be related to the reactions of o-tolylphenyl ketone and similar derivatives: P. G. Sammes, Photoenolization, Tetrahedron 1976, 32, 405-422.

${ }^{13}$ J. A. Mayer, Understanding Hydrogen Atom Transfer: From Bond Strengths to Marcus Theory, Acc. Chem. Res. 2011, 44, 36-46. J. Jung, S. Kim, Y.-M. Lee, W. Nam, S. Fukuzumi, Switchover of the Mechanism between Electron Transfer and Hydrogen-Atom Transfer for a Protonated Manganese(IV)-Oxo Complex by Changing Only the Reaction Temperature, Angew. Chem. Int. Ed. 2016, 55, 7450-7454. 